\title{
ASSESSMENT OF THE IMPACT OF CHANGES IN THE FISCAL POLICY INSTRUMENTS ON THE LEVEL OF FINANCIAL - ECONOMIC INEQUALITY OF MUNICIPALITIES OF RESOURCE REGIONS OF RUSSIA
}

\author{
Prof. Dr. Evgenya B. Bukharova \\ Dr. Anna R. Semenova \\ Dr. Natalia V. Nepomniashaya \\ Dr. Svetlana N. Grib \\ Siberian Federal University, Russia
}

\begin{abstract}
The research paper focuses on assessing the impact of the tools of the fiscal policy of the country for the resource regions and municipalities development in the context of the current budget federalism and inter-budget relations. Krasnoyarsk Krai - the largest in its area and the availability of natural resources region of Russia is considered as a model resource region. The Krai's role in the Russian economy as well as its financial and social well-being are largely determined by the resource model of the economic development of the country. The article proposes an approach to the typology of the resource region municipalities, taking into account the level of the socio-economic and financial conditions differentiation between the municipalities and the level of sensitivity to the changes in the institutional conditions of the fiscal policy of the country. The results obtained in the article are based on the panel research of Krasnoyarsk Krai municipalities and the use of the econometric models with fixed effects.
\end{abstract}

KEYWORDS: budget federalism, financial potential, resource economics, spatial inequality, asymmetry of economic development

\section{INTRODUCTION}

The Russian Federation is characterized by a high degree of heterogeneity and imbalance of economic space, which is marked in almost all the aspects of social and economic development. For many decades, the standard of living of the population and the level of socio-economic development in regions vary greatly, there remains a significant gap in the levels of economic development of the territories. The analysis of the factors of interregional differences in Russia in the post-Soviet period is reflected in the works of Russian and international researchers [1], [2]. Currently, the issues of influence of the factors of socio-economic differentiation of regions on the spatial economic inequality and asymmetry in social and economic development under conditions of different models of spatial development and budget federalism models are actively discussed in the literature [3], [4].

At that, budget federalism model is regarded as a system of budgetary relations between the three levels of budgetary system - federal authorities, authorities of the federation 
subjects and local governments based on the decentralization of fiscal rights and powers between the parties and, at the same time, while federal center maintains the dominant position in vertical relations [5].

In this context solving the problems of reducing interregional contrasts, gaps and variations in socio-economic development on the basis of formation of the effective spatial economic structure of the country and the tools for financial and economic regulation are of particular relevance and importance. Under conditions of crisis development and the growth of internal and external imbalances it is evident that the regions are the sources for the formation and maintenance of stability in the Russian economy, and municipalities are the source of the regions - federal subjects' safety. In this regard, the assessment of stability, balance and asymmetry of sub-regional systems of any level is of relevance and cannot be assessed independently, as its development is supported by a complex conglomerate of external and internal relations [6].

The Russian Federation is a unique federal state, which, on the one hand, entrusts its territorial entities - regions and municipalities with ample financial and economic powers in the field of economic regulation. But, on the other hand, within the framework of budget federalism the current system of rules and regulations that controls intergovernmental fiscal relations of the regions and the federation with a high degree of financial resources centralization, leads to the fact that the regions do not have sufficient capacities to accumulate internal financial resources to ensure their balanced economic growth [7]. Municipalities are the most vulnerable in the system of inter-budgetary relations in Russia [8].

The research, which the present article is devoted to, is focused on studying the issues of influence of the tools of financial and tax regulation of inter-budget relations on both the levels of the resource regions development and sub-regions within them under conditions of intraregional social and economic asymmetry. Currently, 25\% of Russia's regions belong to the regions with resource economies. At that, more than $50 \%$ of federal budget revenues are generated due to the tax revenues from economic activities of the resource regions. Therefore, the effectiveness of federal fiscal policy and the applied tools to a large extent are determined by the fact how these tools will stimulate economic development in the resource regions. Localization of economic activity related to the resource economy is taking place in sub-regions-municipalities of the regions-subjects of the Federation. For this reason, the possibilities of economic growth in the resource industries are largely dependent on socio-economic level, business environment and the population living in cities and towns of the municipalities. The research is conducted Krasnoyarsk Krai - dynamically developing, the largest in area and the availability of natural resources region of Russia.

\section{MATERIALS AND METHODS}

The methodological approach to the solution of the problem set is of complex nature and includes development of the integrated indicators of economic, financial and social state of the region and its municipalities' economy; development of a model instrument for the monitoring of economic and social development of the region. The research methodology is based on the use of the applied econometric models system with deterministic effects that are based on the dynamic information base of longitudinal observations on the representative samples in the context of municipalities. 
Economic and mathematical, as well as econometric models and methods of computer analysis and spatial development forecasting are widely used in the world practice of decision making in the field of territorial management [9]. The novelty of this research is connected with the development of econometric methods and the system of spatial economic models, based on the panel (longitudinal) studies that allow studying spatial development of both the region's economy as a whole and its individual components, as well as to assess the power of influence on the level of the region development of both individual specific management decisions and systemic changes [10]. Using computer models for processing longitudinal studies and econometric models system allows specifying the methods to assess spatial asymmetry of the municipalities' development. The use of the panel studies' information base, taking into account international practice of the Russian regions development analysis allows making statistically reliable comparisons with the regions of other countries [11]. Practical approbation of the proposed models and methods has been performed with the use of the information from the Federal State Statistics Service of the Russian Federation ${ }^{1}$ and the Federal State Statistics Service of the Krasnoyarsk Territory ${ }^{2}$ for 2007-2014. For the region as a whole, and the municipal areas the list of comparable indicators has been used.

\section{RESULTS}

The impact of the fiscal policy of Russia and development potential of the resource regions - subjects of the federation. Social and economic situation of municipalities as the third level in the system of vertical inter-budgetary relations of the country is largely dependent on the economic situation of the federation subject, its financial potential, type of settlements within municipalities and regions of the subject, and the existing level of intra-regional social and economic asymmetry of the region.

Thus, in the early 2000s the current system of inter-budget relations, in which a significant amount of the federal budget revenues is generated due to distribution of the tax and non-tax revenues collected in the regions, was formed. One of the objectives for sustainable development both at the national level and for the regions-subjects of the Federation is smoothing imbalances between different types of territorial entities of all levels. Therefore, the process of eliminating discrepancies between the amount of each level of government obligations on expenditures with profit potential of budgets of all levels in the vertical: federal budget - regional budgets - local budgets is carried out on the basis on vertical alignment procedures through financial transfers from the budgets of higher levels.

However, even before becoming established, the basic model of budget federalism in the country starts being continuously reformed, both in terms of the public powers delegation from one level to another, and in terms of changes in income fixing conditions: the distribution of tax and non-tax revenues between the federal and regional levels of the budget system and budget transfers allocation. Without paying specific attention to all the decisions to change the rules of budgeting, it should be noted that the most important decisions made at the federal level, such as social benefits monetization, social workers' salary increase, changes in the system of financing sectors of budgetary

\footnotetext{
${ }^{1}$ http://www.gks.ru/wps/wcm/connect/rosstat_main/rosstat/ru/statistics/databases/emiss/

${ }^{2}$ http://www.gks.ru
} 
power to a large extent "laid on the shoulders of" regional budgets in terms of increasing expenditures of regional and municipal budgets. Despite the increase in expenditures, up to 2008 the resource regions, as a rule, had budgets with balanced revenues and expenditures due to their own tax base, and partly due to the financial transfers from the federal budget.

Under the influence of the global financial and economic crisis and the prolonged recession in Russia the problems of the federal budget balance are increasing. For this reason within the frames of inter-budget relations the share of exemptions of the tax and non-tax revenues collected in the regions to the federal budget has been steadily increasing for the last 5 years. In this sense, the situation developing in the state-financed organization of Krasnoyarsk Krai is very indicative (Fig. 1$)^{3}$.

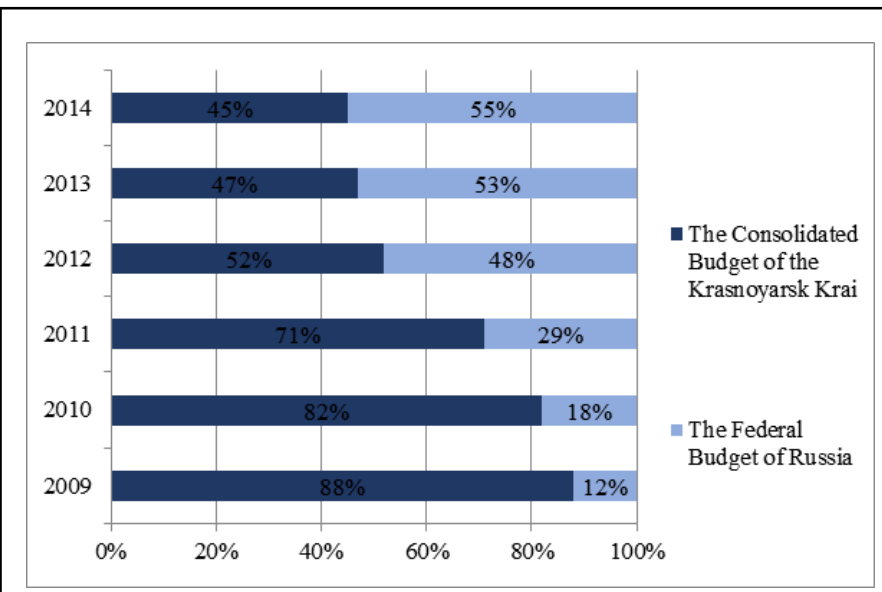

Fig. 1. Distribution of tax and non-tax revenues collected in Krasnoyarsk Krai between the federal budget and the consolidated budget of Krasnoyarsk Krai, 2014.

In $201455 \%$ of all tax revenues collected in the territory of the region, were transferred to the federal budget (in $2009-12 \%$ ), which is 6 times more than the volume of reverse transfers from the federal budget into the consolidated budget of Krasnoyarsk Krai. As a result, the growth of the budget revenue measures in the recent years yields the rates of economic development. Thus, the gross regional product of the region during this period increased by $30 \%$, with the growth of the Krai budget revenues only by $8 \%$. So, starting from 2010, the federal budget revenues from the Krai, taking into account customs duties, have increased by more than 8.7 times. At the same time, the budget's own tax revenues increased by $1 \%$ for the period. The reduction in the Krai budget revenues was significantly influenced by the federal decision to introduce from 01 January 2012 Article 3.1 of the Tax Code of the Russian Federation on taxation of the consolidated groups of taxpayers ${ }^{4}$, which resulted in a $6 \%$ decline in the regional budget revenues from income tax.

All this is taking place against the background of the regional budget expenditure obligations growth. As a result, since 2009, Krasnoyarsk Krai has had negative deficit, which has increased over this period by 31\%, while borrowings for the budget deficiency payment are growing as well due to the lack of its own revenues. Due to the unbalanced budgetary policy of the Russian Federation, the consolidated public debt of the region for the last 9 years has increased by more than 50 times, and the ratio of the region's public debt to the tax and non-tax revenues of its budget amounted 59\% in 2015. There is a paradoxical situation, when the region's economic activity is actively

\footnotetext{
${ }^{3}$ Calculated according to the data from the Ministry of Finance of Krasnoyarsk Krai

${ }^{4}$ Tax Code of the Russian Federation URL: http://base.garant.ru/10900200/
} 
developing and strengthening its positions as the federal budget donor and, at the same time, has a large budget deficit and the amount of borrowing.

Krasnoyarsk Krai possesses typical for the resource regions characteristics: low population density; population concentration and scattered settlements in the Krai territory in different natural-climatic zones; low level of intra-regional transport infrastructure development; a vast range of types of settlements-agglomerations; a high degree of urbanization. The combination of these conditions determines intra-territorial differentiation of the economic development factors and the asymmetry of the socioeconomic situation of the municipalities.

Types of municipalities. In the course of analysis the primary grouping of Krasnoyarsk Krai municipalities is based on the administrative division of the region and takes into account the level of urbanization and the types of settlements with account of specialization. The four types of formations have been identified: 1. Urban districts small towns, medium-sized towns and big cities, including Krasnoyarsk as a center of agglomeration; 2. Municipal areas, which include non-urbanized settlements and urban settlements, which, as a rule, are administrative centers; 3. Municipal areas, which include only non-urbanized settlements and which population is employed in the sectors of agriculture and timber harvesting; 4. Municipal areas, which include non-urbanized settlements of permanent and temporary residence, and which specialize in the largescale extraction of natural resources.

Assessing the asymmetry of social and economic situation of the municipalities. The information base of panel observations to assess asymmetry in 57 municipalities of the region consists of three groups of indicators. Economic indicators group includes 18 indicators that characterize the volume of the shipped goods of own production, investments, revenues and expense of the region's budget, labor productivity, etc. The second group of social development indicators includes 17 indicators related to the population dynamics, the level of income, the state of the social sphere, the provision of services to the public, etc. The third group of indicators includes 19 parameters and characterizes the quality of the environment and the areas ecology 5 . Two integrated indicators have been developed to assess asymmetry: the integrated indicator of the economic status level, calculated as a normalized sum of the ranks of economic indicators of panel observations and the integrated indicator of social status, calculated on the second and the third group of indicators. The level of asymmetry changes over the years from 2007 to 2014 is assessed on the basis of 2-dimensional representation of the integrated indicators deviations in municipalities from the average values for the Krai, that 2014 is graphically represented in Fig. $2^{6}$.

\footnotetext{
${ }^{5}$ Indicators on all the groups correspond with the data from the Krasnoyarsk Krai Territorial Branch of the Federal State Statistics Service. URL: http://www.gks.ru

${ }^{6}$ In Fig. 2 X-axis represents the deviation of the values of the integral index of the Krai municipalities' economy state from the average for the Krai; Y-axis is deviation of the integral index value of social development. Individual values of integral indexes deviation for the areas are indicated by points (markers.) To display individual values for towns yellow marker is used; for non-urbanized municipal areas - blue marker, for municipal areas, which include urban settlements - green marker, for nonurbanized municipal areas that specialize in large-scale extraction of natural resources - pink marker. The most remote from the axes marker corresponds to a larger individual exceeding of the integral index value of the municipality above the average for the region
} 
At that, localization on the graph points quadrants, calculated as a deviation of the integral indexes values of economic and social state from the medium ones in the Krai for each municipality, allows evaluating the level of socio-economic asymmetries and classify the municipalities into 4 groups:

1. Municipal areas that have lower levels of economic development and the level of their social development

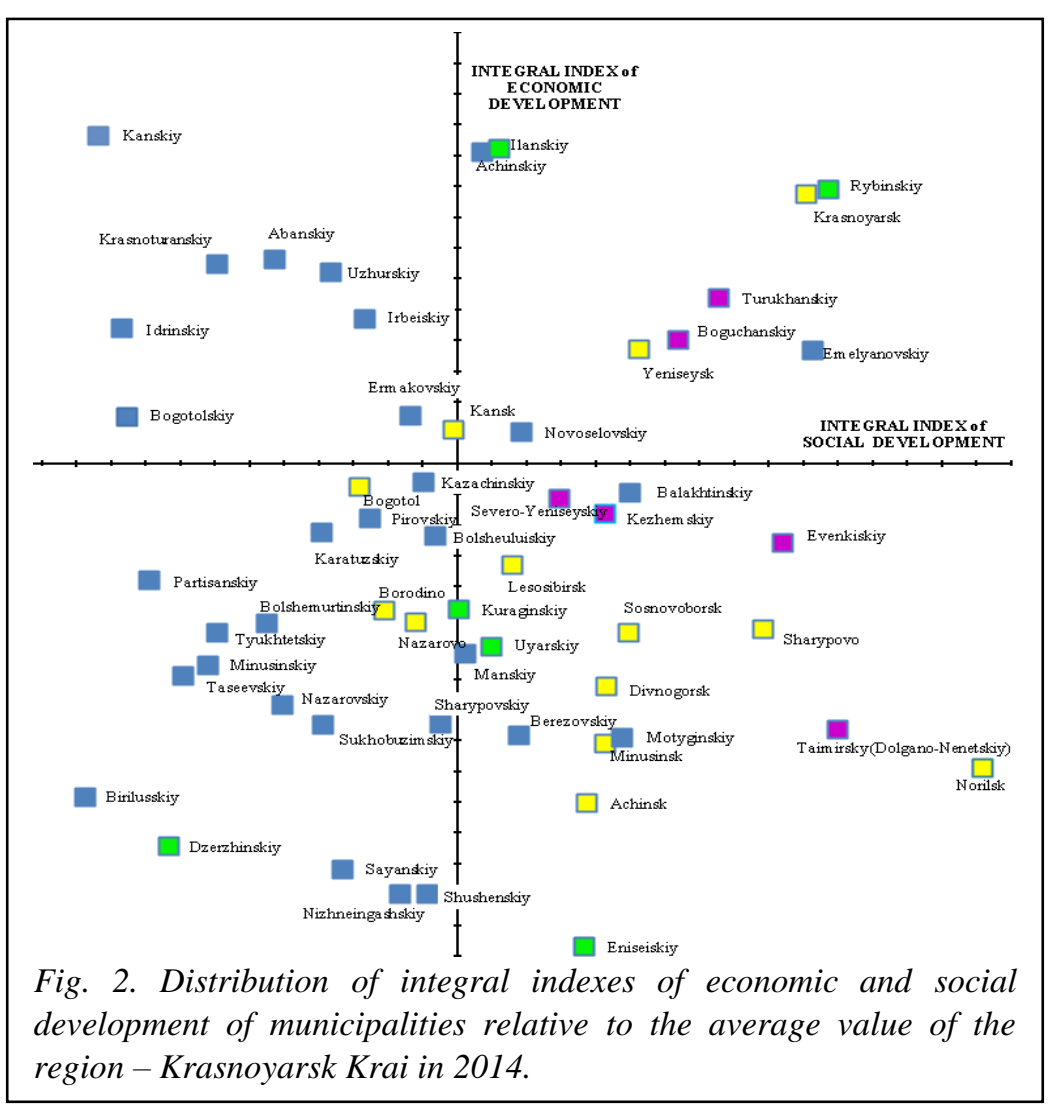
in the Krai is above average ( $1^{\text {st }}$ quadrant). Most areas of this group belong to nonurbanized territories that are in close proximity to the main federal ones;

2. Municipal areas with the both levels of economic and social development above average for the region ( $2^{\text {nd }}$ quadrant). In 2007, this group included 18 municipalities: big cities Krasnoyarsk and Norilsk; medium-sized towns; nonurbanized areas surrounding large deposits of mineral resources and non-urbanized areas bordering with the Krasnoyarsk agglomeration.

3. Municipal areas, which both levels of economic and social development are below average for the region ( $3^{\text {rd }}$ quadrant). Most areas of this group belong to nonurbanized territories.

4. Municipal areas, which have higher level of economic development and their level of social development is below average for the Krai ( $4^{\text {th }}$ quadrant). Most areas of this group belong to non-urbanized territories that are in close proximity to the main federal ones.

The dynamics of two-dimensional measurement for the yeas from 2007 to 2014 demonstrates, that the level of spatial inequality and asymmetry of the economic situation of the territories is primarily localized at the level of municipalities within the region-subject of the Federation and is strengthened under the influence of changes in the fiscal regulation of inter-budgetary relations carried out in this period. The problems of the territories' spatial inequality and asymmetry of the economic situation are primarily localized at the level of the municipalities within the region-the federation subject. Since municipalities have limited financial and investment sources for independent intra-regional economic policy, at the municipal level the potential for 
economic development is extremely sensitive to the changes in the federal legislation. Thus, for instance, the municipalities' opportunities to increase the financial resources on their own are rapidly decreasing due to withdrawal of the major part of the received tax revenues

Thus, changes of budgetary policy in the framework of budget federalism led to the fact that in 2014 only 8 out of 18 municipal areas had above average economic and social level for the region. These include the city of Krasnoyarsk and non-urbanized areas bordering with the agglomeration and having diversified economy; non-urbanized resource areas, where large investment projects on new deposits development were implemented at that period and a few small towns and non-urbanized areas bordering with the main highways. Single-industry towns Norilsk, Borodino and most mediumsized towns and non-urbanized areas of the Far North worsened their social conditions, but preserved their economic level. In most non-urbanized areas both the level of economic development and the level of social development have decreased.

Asymmetry gain is confirmed by multivariate econometric analysis of the panel study indicators and the carried out hierarchical clustering of homogeneous panel indicators into the homogeneous groups of areas according to the degree of the observation subjects connectivity every year. The socio-economic differentiation has increased under the influence of interbudget relations changes, so 5 homogeneous cluster areas were allocated in 2007, and the number increased up to 8 homogeneous clusters in 2014. The increase of homogeneous clusters number was due to the growth of asymmetry between the Krasnoyarsk agglomeration (with the surrounding areas) and medium-sized cities, small towns and non-urbanized territories.

\section{CONCLUSIONS}

1. Within the framework of the current principles of budget federalism and interbudgetary relations under conditions of economic recession these are the resource regions that in the first place take on the financial burden of the country's budget balance. The growing need in balancing the consolidated budget of the Russian Federation under conditions of recession leaves to the regions, including the resource regions, fewer funds for their own development. At that, Krasnoyarsk Krai, as a typical resource region, is rapidly deprived of opportunities to correct internal imbalances on its own, as there is a sharp deterioration in providing the territory with its own financial resources, and it does not have an opportunity to accumulate financial resources for economic growth and improve the population's quality of life.

2. Inter-regional asymmetry of socio-economic situation of the region's municipalities is determined by the total of differentiated conditions connected with natural and climatic factors, geographical location, economic specialization and the level of diversification, population density, the level of the territory transport facilities development and the level of urbanization and the type of settlements.

3. The four types of municipalities identified on the basis of combining the types of urbanized and non-urbanized settlements, taking into account economic specialization, react to the changes in the federal fiscal policy in different ways.

4. Changes in the tools and rules of inter-budgetary relations strengthen intra-regional economic and social asymmetry of the municipalities' situation. 
5. To a lesser extent fiscal changes affect the relative position: of big cities and nonurbanized towns bordering with the agglomeration; non-urbanized resource areas, where large investment projects on new deposits development were implemented at that period; small towns and non-urbanized areas bordering with the main highways. They preserve their level of economic and social development above average for the Krai.

\section{ACKNOWLEDGEMENTS}

The study was supported by Russian Fund of Humanities and Krasnoyarsk Science Foundation within the framework of grant 15-12-24007 - "Methodological Approaches to the Applied Analysis Models Development and Forecasting Economics Development of the Resource Regions of Russia under Conditions of Spartial Inequality and Asymmetry (Through the example of Krasnoyarsk Krai)".

\section{REFERENCES}

[1] Granberg A.F., Current Issues of Regional Development and Regional Policy. Federalism, issue 2, pp. 9-26, 2001.

[2] Ahrend, R. Speed of Reform, Initial Conditions or Political Orientation? Explaining Russian Regions' Economic Performance, Post-Communist Economies, vol. 17/ issue 3, pp. 289-317, 2005.

[3] Zubarevich N.V., Sagronov S.G., Inequality of Social and Economic Development of the Regions and Towns of Russia in the 2000s: Growth or Decrease? Social Sciences and Modernity, issue 6, 2013.

[4] Oates W., Fiscal Federalism, N.Y, Harcourt, Brace, Jovanovich, 1972.

[5] Shuba V.B., Formation and Development of Inter-Budgetary Relations, M., Economist, 238 p., 2004.

[6] Bukharova E.B., Samusenko S.A, Semenova A.R., Complex Assessment of Economic Security of the Resource Type Region. Region: Economics and Sociology, vol. 4/issue 92, pp. 113-138, 2016.

[7] Zubarevich N.V., Regional Development and Regional Policy in Russia, ECO Journal, issue 4, pp. 7-27, 2014.

[8] Tatarkin A.I., On Anti-Crisis Activities of Municipalities, Region: Economy and Sociology, issue 2, pp. 137-155, 2009.

[9] Arbia G., Spatial Econometrics. Statistical Foundations and Applications to Region Convergence, Springer, 2006.

[10] Frees E.W., Longitudinal and Panel Data: Analysis and Applications in the Social Sciences, Cambridge University Press, 2004.

[11] OECD Territorial Reviews: The Krasnoyarsk Agglomeration, Russian Federation. OECD Publishing, Paris, 158 p., 2015. URL://dx.doi.org/10.178/97890264229372-en 